\title{
FISIOTERAPEUTA E A SAÚDE DO IDOSO NA ATENÇÃO BÁSICA
}

\section{ARTIGO DE REVISÃO}

SANTOS, Karen Christina Rodrigues dos ${ }^{1}$

SANTOS, Karen Christina Rodrigues dos. Fisioterapeuta e a saúde do idoso na atenção básica. Revista Científica Multidisciplinar Núcleo do Conhecimento. Ano 05, Ed. 07, Vol. 01, pp. 153-160. Julho de 2020. ISSN: 2448-0959, Link de acesso: https://www.nucleodoconhecimento.com.br/saude/fisioterapeuta-e-a-saude

\section{RESUMO}

O envelhecimento é um processo que envolve diversos fatores, sendo fundamental que os profissionais atuem de forma global e integral. $O$ envelhecimento populacional está ligado à mudança de alguns indicadores de saúde, especialmente a queda da fecundidade e da mortalidade e o aumento da expectativa de vida. O objetivo deste estudo foi discorrer sobre a importância da atuação do fisioterapeuta na saúde do idoso na atenção básica. $O$ desenvolvimento da pesquisa bibliográfica terá como base, autores nacionais e internacionais, sendo utilizadas pesquisas em livros, bancos de dados e bases de dados como Lilacs, Scielo, Google Acadêmico, no período entre 1994 e 2016. A saúde do idoso envolve vários eventos, um exemplo são as quedas, que são multifatoriais de alta complexidade terapêutica, exigindo um trabalha incansável na prevenção, para tanto, é necessária uma equipe multiprofissional da

\footnotetext{
${ }_{1}^{1}$ Mestrado Ensino na Saúde, UFRGS. Especialização em Saúde e Segurança no Trabalho - Instituto Prominas Serviços Educacionais, PROMINAS. Especialização em Especialização em Gerontologia e Saúde Mental -Instituto Prominas Serviços Educacionais, PROMINAS. Especialização em Gestão em Saúde EaD - Universidade Federal do Rio Grande do Sul, UFRGS. Especialização em Especialização em Didática do Ensino Superior - Faculdade de Educação da Serra, FASE. Especialização em Saude Publica - Fundação Oswaldo Cruz, FIOCRUZ. Graduação em FISIOTERAPIA - Universidade de Taubaté, UNITAU.
} 
qual o fisioterapeuta faz parte. Muitos foram avanços quanto a inserção do profissional fisioterapeuta na atenção básica, bem como, as ações voltadas para a saúde do idoso são de suma importância, necessitando de uma equipe cada vez mais preparada e completa, principalmente com a atenção do profissional fisioterapeuta.

Palavras-chave: Fisioterapia Geriátrica, envelhecimento, fisioterapia na Atenção Básica.

\section{INTRODUÇÃO}

O envelhecimento possui um mecanismo multifatorial, esses fatores interagem na regulação do funcionamento típico e atípico do indivíduo, por isso é importante que o profissional, pacientes e todos que o rodeiam, tenham uma visão global desse processo (SANTOS; ANDRADE; BUENO, 2009).

Segundo Brasil (2007), estima-se que em 2050 existam cerca de dois bilhões de pessoas com sessenta anos ou mais no mundo, a maioria delas vivendo em países em desenvolvimento. No Brasil, em 2025 serão 33 milhões de idosos, é a oportunidade de inovar nos campos da Geriatria e da Gerontologia (SCHNEIDER, 2010; GRAVE; ROCHA ; PÉRICO, 2012).

Nesse contexto, é preciso que as instituições de ensino se preparem para essa nova realidade. Entendendo que o país está envelhecendo e que os profissionais devem ser capacitados e preparados para o atendimento adequado aos idosos, pois através do ensino é possível moldar o futuro profissional para que ele pense de forma global, ética, atuando no contexto onde seus pacientes estão inseridos (FREITAS, 2016; GRAVE, ROCHA; PÉRICO, 2012).

Para Grave; Rocha e Périco (2012), fisioterapia geriátrica deve ter como objetivo a reinserção social dentro dos aspectos preventivos e curativos, sendo necessária uma abordagem que ultrapasse o modelo centrado no médico, valorizando os aspectos multidimensionais do idoso. 
Muitos são os entraves para a inserção definitiva do fisioterapeuta na atenção básica, bem como há ineficiência de profissionais específicos para promoção de saúde dos idosos, apesar da ESF ser a porta de entrada do SUS (CONCEIÇÃO et al., 2013).

Este trabalho teve como objetivo discorrer sobre a importância atuação do fisioterapeuta na saúde do idoso na atenção básica. Nesta perspectiva, a questão que norteou este trabalho foi: A atuação do profissional fisioterapeuta junto ao público da terceira idade na atenção básica é importante?

O presente trabalho foi uma pesquisa bibliográfica que, segundo Gil (2002), é uma pesquisa com base em material já elaborado, constituído principalmente de livros e artigos científicos. O desenvolvimento da pesquisa bibliográfica terá como base, autores nacionais e internacionais, sendo utilizadas pesquisas em livros, bancos de dados e bases de dados como Lilacs, Scielo, Google Acadêmico, no período entre 1994 e 2016, tendo como descritores da pesquisa: fisioterapia geriátrica, envelhecimento, fisioterapia na atenção básica.

\section{DESENVOLVIMENTO}

O envelhecimento populacional está ligado à mudança de alguns indicadores de saúde, especialmente a queda da fecundidade e da mortalidade e o aumento da expectativa de vida. Não acontece da mesma forma para todos os seres humanos, sofrendo influência dos processos relacionados ao gênero, à etnia, ao racismo, condições socioeconômicas, localização geográfica e de moradia. (BRASIL, 2007).

Assis et al. (2002) afirmam que, atualmente, para ser mais saudável não basta apenas estimular e/ou induzir os indivíduos a adotarem condutas adequadas, sem considerar o contexto biopsicossocial e econômico qual estão inseridos. O meio pode gerar o adoecimento, bem como, facilitar ou dificultar a prevenção, o controle e/ou cura das doenças. 
Com base nessa transição demográfica, que prevê mudanças dos paradigmas relacionados ao envelhecimento, foi necessário criar uma política pública que garantisse os direitos dos idosos.

A Política Nacional de Saúde da Pessoa Idosa (BRASIL,2006) traz em seu texto:

Concomitante à regulamentação do SUS, o Brasil organiza-se para responder às crescentes demandas de sua população que envelhece. A Política Nacional do Idoso, promulgada em 1994 e regulamentada em 1996, assegura direitos sociais à pessoa idosa, criando condições para promover sua autonomia, integração e participação efetiva na sociedade e reafirmando o direito à saúde nos diversos níveis de atendimento do SUS (Lei no 8.842/94 e Decreto no 1.948/96).

Para tanto, as equipes de saúde precisam se capacitar e se completar cada vez mais, visando a integralidade e universalidade da atenção oferecida. Começando por conhecer as peculiaridades do envelhecimento nos aspectos biopsicossociais. O fisioterapeuta é originalmente dedicado às ações curativas, porém adaptou-se aos novos preceitos da saúde, atuando de forma preventiva.

Segundo Reis Junior (2007), o fisioterapeuta é fundamental dentro da equipe multidisciplinar, promovendo ao paciente a manutenção da sua identidade, ajuda a manter a vida ativa até a morte, proporciona conforto, treina as habilidades ainda existentes, incentivando a atividade corporal mantendo a autonomia, estimulando o convívio familiar e orientando.

Para Costa e Silva (2010) e Sneider (2010), o envelhecimento apresenta características específicas, abrangendo diversas dimensões, porém os exercícios físicos podem potencializar a capacidade funcional, promovendo melhora significativa na execução das AVDs, minimizando o risco de quedas. As intervenções do fisioterapeuta devem ser programadas com o objetivo de atender as necessidades de cada um, sempre buscando a interação com a equipe visando tornar esse processo de envelhecimento mais digno.

Através de atividades lúdicas, é possível trabalhar a cognição, equilíbrio e fortalecimento muscular, tornando mais segura a realização das ADVs. A manutenção 
da capacidade funcional está diretamente ligada à saúde mental e qualidade de vida do idoso.

Ely et al. (2009) confirmam que a atenção à saúde do idoso deve ter foco principal a manutenção da capacidade funcional do indivíduo que envelhece, implicando na valorização da independência e autonomia do idoso, bem como na conservação de sua máxima capacidade físico-funcional e saúde mental.

Gama (2010) afirma que, apesar da origem reabilitadora do fisioterapeuta, ele pode e deve realizar nos serviços o acolhimento, triagem e avaliação fisioterapêutica, prescrevendo a melhor conduta, estabelecer o prognóstico, tempo de tratamento e orientando os usuários.

Portanto, a mudança deve iniciar nas bases da graduação, visando a formação de um profissional crítico e com um olhar mais abrangente, sendo fundamental investir na educação permanente desses profissionais.

Carvalho (2013) diz que a atuação do fisioterapeuta idealizada na atenção básica deve incidir diretamente na atenção integral ao idoso, sua família e a comunidade, considerando todas as necessidades identificadas no território, contemplando as diversas condições de saúde evidenciadas no cotidiano das equipes. Incentivando a participação da comunidade, promovendo o acesso dos usuários e capacitar profissionais que tenham os conhecimentos necessários à realização de uma atenção resolutiva e de qualidade para a terceira idade.

A saúde do idoso envolve vários eventos, um exemplo são as quedas, que são multifatoriais de alta complexidade terapêutica, exigindo um trabalha incansável na prevenção, para tanto, é necessária uma equipe multiprofissional da qual o fisioterapeuta faz parte, traçando um plano de intervenção que abrange estratégias preventivas e reabilitadoras (SOARES; RECH, 2015).

O fisioterapeuta possui uma visão completa das necessidades do idoso, compreende os aspectos físicos e suas implicações na saúde mental.Estudos comprovam que há receptividade por parte dos idosos quando na presença de um fisioterapeuta na ESF, 
pois esse profissional que atua principalmente na prevenção e promoção à saúde, obtendo resultados positivos, colaborando para a manutenção da funcionalidade, concordando com Maia et al. (2015) que afirma que há diminuição no tempo de tratamento e, consequentemente, desonerando o sistema.

Nascimento et al. (2013) realizou um estudo baseado na atuação do fisioterapeuta na UBS, através medicina chinesa e atendimentos nas diversas áreas da fisioterapia para os idosos da demanda da unidade, verificando viabilidade para a atuação do fisioterapeuta, essa experiência mostrou que iniciativa é um modelo do ponto de vista assistencial e acadêmico para garantir maior resolutividade nas ações de saúde voltadas para a terceira idade na atenção básica.

\section{CONCLUSÃO}

A atenção à saúde do idoso conquistou espaço no cenário da saúde pública, as ações propostas visam, principalmente, a prevenção de agravos decorrentes do envelhecimento e promoção de qualidade de vida para a população da terceira idade.

Muitos foram avanços quanto a inserção do profissional fisioterapeuta na atenção básica, bem como, as ações voltadas para a saúde do idoso são de suma importância, necessitando de uma equipe cada vez mais preparada e completa, principalmente com a atenção do profissional fisioterapeuta.

Recomenda-se que mais estudos sejam realizados, com a finalidade de reforçar as contribuições do fisioterapeuta na atenção básica, principalmente nas atividades direcionadas aos idosos, principalmente no aspecto da saúde preventiva.

\section{REFERÊNCIAS}

ASSIS, M. (Org.) Promoção da saúde e envelhecimento: orientações para o desenvolvimento de ações educativas com idosos. Rio de Janeiro. CRDE UnATI UERJ, 2002. 146p 
BRASIL. Ministério da Saúde. Secretaria de Atenção à Saúde. Departamento de Atenção Básica. Envelhecimento e saúde da pessoa idosa. Brasília: 2007.192 p Portaria № 2.528 de 19 de outubro de 2006. Aprova a Política Nacional de Saúde da Pessoa Idosa. Disponível em < http://bvsms.saude.gov.br/bvs/saudelegis/gm/2006/prt2528_19_10_2006.html> Acesso em 14 nov. 2016

CARVALHO, F. G. O trabalho da fisioterapia na assistência ao idoso na atenção básica caderno saúde e desenvolvimento. vol.3 n.2 , p 21-34, jul/dez. 2013.

CONCEIÇÃO, A. P. et al. Fisioterapia aplicada à geriatria no PSF: Uma proposta baseada no novo modelo de atenção primária. Fisioscience, ano 2, v. 3, n.2, p. 2851, Jul/Dez. 2013.

ELY, J. C. et al. Atuação fisioterápica na capacidade funcional do idoso institucionalizado. RBCEH, Passo Fundo, v. 6, n. 2, p. 293-297, maio/ago. 2009.

FREITAS, V. M. Formação dos profissionais de saúde para o atendimento domiciliar ao idoso: desafio a ser superado. Cadernos de Publicações do Centro Universitário UNIVAG, Várzea Grande, n.5, p. 31-36, 2016. Disponível em < www.periodicos.univag.com.br/index.php/UNIVAG2015/article/download/299/539> Acesso em 08 Jul 2016.

GAMA , K. C. S. D., Inserção do fisioterapeuta no Programa de saúde da família: uma Proposta ética e cidadã. C\&D-Revista Eletrônica da Fainor, Vitória da Conquista, v.3, n.1, p.12-29, jan./dez. 2010.

GIL, A. C. Como elaborar Projetos de pesquisa. 4.ed. São Paulo: Atlas, 2002. 175p.

GRAVE, M., ROCHA, C. F., PÉRICO, E. A formação do profissional fisioterapeuta na atenção à saúde do idoso: uma revisão integrativa. RBCEH, Passo Fundo, v. 9, n. 3, p. 371-382, set./dez. 2012. 
MAIA et al. Importância da inclusão do profissional Fisioterapeuta na atenção básica de saúde. Rev. Fac. Ciênc. Méd. Sorocaba, v. 17, n. 3, p. 110 - 115, 2015

NASCIMENTO, R,G. et al. Fisioterapia gerontológica na atenção primária à saúde: uma experiência na região norte. Revista Ciência \& Saúde, Porto Alegre, v. 6, n. 3, p. 222-228, set./dez. 2013.

REIS JÚNIOR, L. C, REIS, P. E. A. M. Cuidados paliativos no paciente idoso: o papel do Fisioterapeuta no contexto multidisciplinar. Fisioterapia em Movimento, Curitiba, v. 20, n. 2, p. 127-135, abr./jun.2007.

SANTOS, F. H., ANDRADE, V. M., BUENO, O. F. A. Envelhecimento: um processo multifatorial. Psicologia em Estudo, Maringá, v. 14, n. 1, p. 3-10, jan./mar. 2009.

SCHNEIDER, A. R. S. Envelhecimento e quedas: a fisioterapia na promoção e atenção à saúde do idoso. RBCEH, Passo Fundo, v. 7, n. 2, p. 296-303, maio/agosto 2010.

SOARES, I.G.E., RECH, V. (2015, outubro-dezembro). Prevalência de quedas em idosos institucionalizados no Brasil: uma revisão integrativa. . Revista Kairós Gerontologia. São Paulo, 18(4), p 47-61, outubro/dezembro 2015.

Enviado: Julho, 2020.

Aprovado: Julho, 2020. 